\title{
Internet Art, Google and Artistic Practice
}

\author{
Elisavet Christou \\ Lancaster University \\ Lancaster, UK \\ e.christou@lancaster.ac.uk
}

\section{INTRODUCTION}

This paper examines the ways Google - through its technologies, services and platforms - is massively influencing contemporary artistic production. The paper presents important Internet artworks as case studies and analyses the different ways artists are using to examine the world and the Internet through Google's platforms and services.

\section{GOOGLE AS INTERNET EXPERIENCE}

Historically, Internet art has been using and exploring all aspects of Internet and the web. Google as a monopoly platform (Srineck 2017), holds a strategic position in digital economy and massively influences how people use the Internet. Most artists who deal with the Internet are finding inspiration and material online using Google's services and platforms (Muir 2014).

Google technologies and services are not new, however their potential for artistic action and intervention keeps growing along with every new Google service, technology and platform. As Google is moving into the consumer internet of things, self-driving cars and virtual reality it becomes a ubiquitous platform across the economy and as a result, more and more artists are using Google to expose, reflect on and examine life online. Artists who use Google technologies and services are not simply revealing/commenting on our contemporary experiences with the Internet, they are also providing us with scenarios for Internet futures.

\subsection{Surfing the Internet for material}

I'm Google by Dina Kelberman (Kelberman 2013) is an on-going project that exists as a Tumblr blog consisting of images found on Google Image Search and videos found on YouTube. The images and videos correspond with one another in form, subject matter, or theme and are arranged in a grid that expands as the user scrolls. It is described by the artist as a stream of consciousness and it portrays the artist's experience using Google Search hunting for obscure information and encountering unexpected results. The blog serves as a visual representation of this phenomenon.
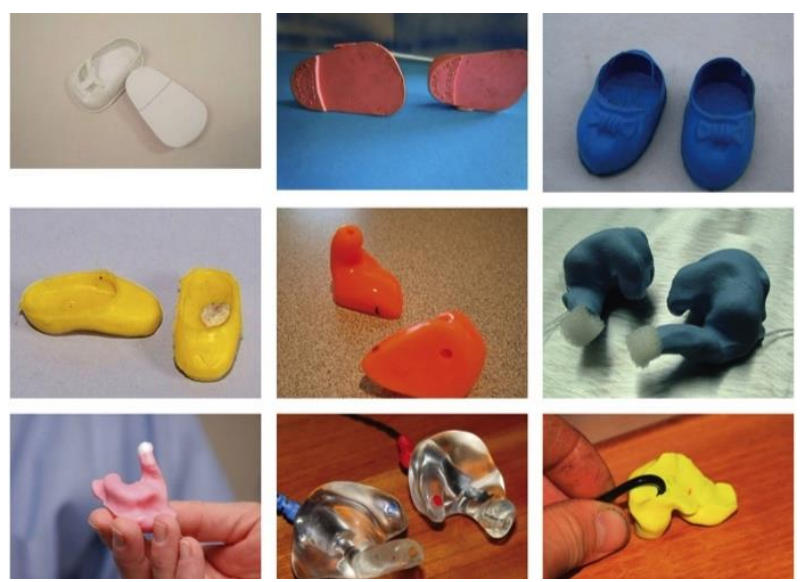

Figure 1: Detail from "I'm Google" (Tumblr still). Image courtesy of the artist.

Jon Rafman's on-going project The Nine Eyes of Google Street View (Rafman 2011) reflects the tension between the human gaze and that of the automatic camera. The "nine eyes" in the title refers to the number of cameras on the pole attached to the top of a Google Street View car; the number has since increased to 15 (Rowland \& Ingraham 2017). The artist does long marathon runs of exploring Google Street View collecting images on a Tumblr account that fall under four categories:

(i) Street photography.

(ii) Photos of natural beauty.

(iii) Surreal images.

(iv) People responding to the Google camera.

The project emerged by the practice of surfing the Internet for inspirational finds. The artist views surfing the Internet as an inherent, intrinsic part of his artistic practice. 


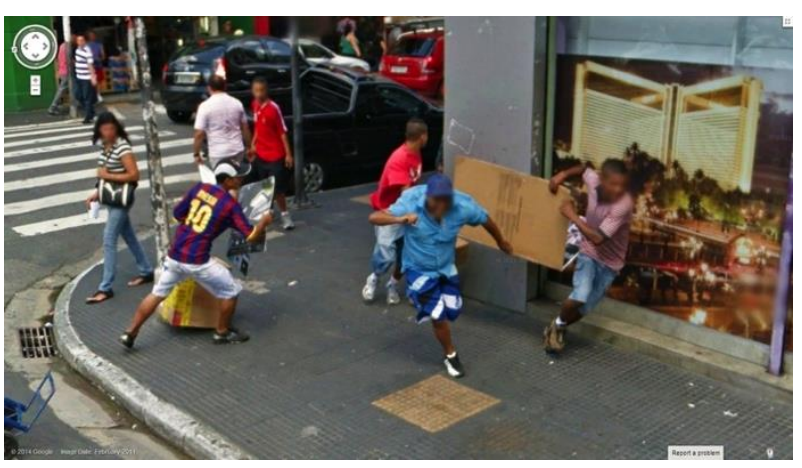

Figure 2: Detail from "The nine eyes of Google Street View" (Tumblr still). Image courtesy of the artist.

\subsection{Exposing Internet realities}

Artist Erica Scourti wrote a diary page using Gmail and then sent it out to herself every day for a year. Using her webcam, she filmed the series of suggested keywords and the links to groups of relevant ads. By creating a Gmail diary, Scourti is aware that Google will "read" her private pages and she tries to present the connection between the human and the algorithmic diaries and therefore between two possible "self-narratives". The artwork, called Life in AdWords (Scourti 20122013), is a 70-minute video where the artist recites strings of "adwords". The artist exposes the workings of Google's codification/algorithmic system by highlighting the language produced by Google AdWords.

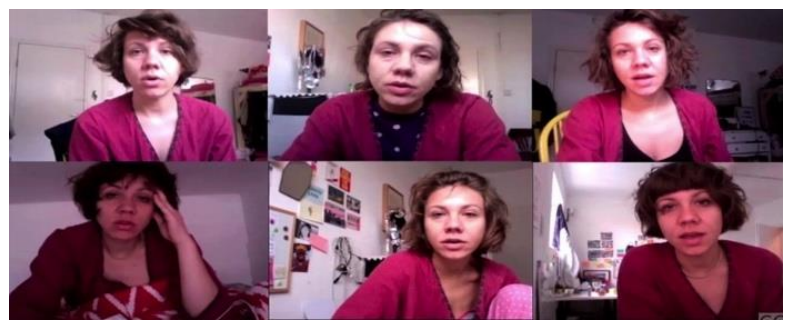

Figure 3: Detail from "Life in AdWords" (Stills from Vimeo video). Image courtesy of the artist.

Adam Overton's Recipe for a Google Party (Overton 2007) invites people to follow his instructions and throw their own Google Party. A Google party is a costume party where the attendees dress up like people they have located while Googling their own names. The instructions read: Go to Google and search for instances of your full name...After searching for a bit, choose the alter-ego who seems the most interesting and try to figure out how this person might dress...Be sure to keep your eyes for clues that might indicate a time period or location, especially if your source is a news article, historical document or obituary...Finally, dress to impress at your next
Google Party and live up as your alter-ego. Created in 2007, Google Party is an early exploration of identity based on online data and search engine algorithms.

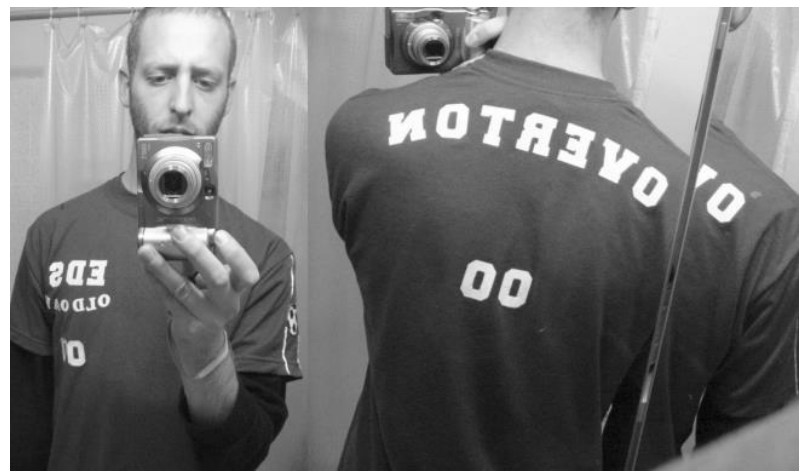

Figure 4: Artist Adam Overton dressed as English teenage football player Adam Overton, Halloweeb 2005. Image courtesy of the artist.

\section{CONCLUSION}

The extended use of Google services and platforms in contemporary Internet artworks reveals new information about how Google is massively affecting our online experiences and thus becomes a fertile ground and an important factor in contemporary artistic practice.

\section{REFERENCES}

Kelberman, D. (2013-ongoing) I'm Google, Tumblr Blog. http://dinakelberman.tumblr.com (retrieved 1 January 2018).

Muir, G. (2014) The Telegraph. Interview by Alice Vincent. https://www.telegraph.co.uk/culture/art/artfeatures/11130492/How-has-the-internet-changedart.html (retrieved 1 January 2018).

Overton A. (2007) Recipe for a Google Party. Leonardo, 40(1):30.

Rafman, J. (2011-ongoing) The Nine Eyes of Google Street View, Tumblr Blog. http://9-eyes.com (retrieved 1 January 2018).

Rowland L. A., and Ingraham C. (2017) How Google Street View became fertile ground for artists. https://theconversation.com/how-googlestreet-view-became-fertile-ground-for-artists-77845 (retrieved 1 January 2018).

Scourti, E. (2012-2013), Life in AdWorlds, video on Vimeo and YouTube. https://vimeo.com/39677781 (retrieved 1 January 2018).

Srineck, N. (2017) Platform Capitalism. Polity Press, Cambridge. 